\title{
O ICMS ECOLÓGICO COMO INSTRUMENTO DE POLÍTICA PÚBLICA AMBIENTAL NO ESTADO DO PARÁ
}

\author{
Mauro Pontes Gonçalves ${ }^{1}$ \\ Lise Tupiassu ${ }^{2}$
}

\begin{abstract}
RESUMO: O objetivo central do artigo é analisar o ICMS ecológico como instrumento de proteção ambiental e desenvolvimento sustentável no Estado do Pará. A utilização de critérios ambientais para distribuição de recursos oriundos do ICMS é recente, sua normatização ocorreu em 2012 e, seus critérios de repartição de receitas ainda necessitam de maiores estudos e aperfeiçoamento no intuito de ampliar sua efetividade para a preservação da natureza. Neste trabalho, analisaremos as receitas recebidas pelos Municípios paraenses, comparando-as com os índices de desmatamento fornecidos pelo Instituto de Pesquisa Ambiental da Amazônia (IPAM), analisando suas congruências e incongruências como política pública ambiental.
\end{abstract}

Palavras-chave: ICMS ecológico, proteção ambiental, desenvolvimento sustentável. Desmatamento. Política pública.

\section{THE ECOLOGICAL ICMS AS NA INSTRUMENT OF PUBLIC POLICY IN THE STATE OF PARÁ}

\begin{abstract}
The objective of the article is to analyze the ecological ICMS as an instrument of environmental protection and sustainable development in the state of Pará. The use of environmental criteria for the distribuition of ICMS resources is recent, and its criteria for revenue sharing still require further studies and refinement in order to increase its effectiveness for the preservation of nature. In this work, we will analyze the incomes received by the municipalities of Pará, comparing them with the deforestation rates provided by the Amazon Environmental Research Institute, analyzing their congruences and inconsistencies as environmental public policy.
\end{abstract}

Keywords: Ecological ICMS.environmental. Protection. Sustainable. Development. Deforestation. Public policy.

\footnotetext{
${ }^{1}$ Advogado. Mestrando em Direito, Políticas Públicas e Desenvolvimento Regional pelo Centro Universitário do Estado do Pará - CESUPA. *mpggpm@gmail.com

${ }^{2}$ Doutora em Direito pela Université Toulouse 1 - Capitole. Mestre em Direito Tributário pela Université’Paris I, Panthéón-Sorbonne. Mestre em Instituições jurídico-políticas pela Universidade Federal do Pará. Mestre em Direito Público pela Université de Toulouse I - Capitole. Professora da Universidade Federal do Pará - UFPA e do Centro Universitário do Estado do Pará - CESUPA. Co-cordenadora da Rede de Pesquisas Junction Amazonian Biodiversity Units Research Networking Program - Jambu RNP. *lise@cesupa.br
} 


\section{INTRODUÇÃO}

A importância da preservação do meio ambiente como fator preponderante para manutenção da vida em nosso planeta, bem como a necessidade de adequação do desenvolvimento econômico à preservação de nosso ecossistema tomou ares de preocupação mundial das nações na segunda metade do século XX.

A Constituição Federal brasileira como garantidora dos direitos fundamentais assevera a atuação do Estado e da sociedade na defesa e preservação do meio ambiente - art. 225, caput, da C.F de 1988 - daí a importância da sociedade na construção de políticas públicas pelo Estado, culminando com a defesa do meio ambiente e o desenvolvimento sustentável.

As políticas de comando e controle mostraram-se insuficientes no combate ao desmatamento, passando o Estado a fomentar a utilização dos tributos como meio de implementação de políticas de proteção ambiental.

A utilização de instrumentos financeiros e tributários como elementos de políticas públicas de preservação ambiental é uma importante ferramenta não só para a defesa do meio ambiente, mas principalmente, para que essas regiões, com os devidos incentivos, possam mudar sua matriz econômica de devastação da floresta para uma economia voltada para o desenvolvimento sustentável, fomentando a manutenção de um meio ambiente saudável e equilibrado, de modo a contribuir, dessa forma, com a melhora da qualidade de vida e, da própria dignidade da comunidade.

Dentro desta perspectiva, no ano de 2012, o Estado do Pará, por meio da lei $\mathrm{n}^{\circ}$ 7.638/2012, normatizou o ICMS ecológico trazendo um novo paradigma na distribuição de receitas aos Municípios vinculado à preservação do meio ambiente.

Em que pese ser o ICMS Ecológico uma política fiscal ambiental utilizada em vários estados brasileiros, ela ganhou contornos específicos no Estado do Pará, de modo que, interessa analisar até que ponto esta política pública, baseada nas transferências intergovernamentais do ICMS, está se construindo enquanto política pública voltada à preservação ambiental na realidade amazônica do Estado do Pará.

Diante disso, este artigo pretende analisar o uso do ICMS ecológico no Estado do Pará como instrumento de política pública ambiental, verificando os resultados obtidos até o momento dentro do binômio, preservação ambiental - incentivos tributários. 
Para esse desiderato, após tratarmos de alguns fundamentos relativos às políticas fiscais ambientais e sua relação com a internalização de externalidades, explanaremos sobre a configuração do ICMS Ecológico no Estado do Pará, analisando os dados relativos à distribuição dos recursos aos Municípios aptos a receber a parcela do ICMS Ecológico em contraste com os números relativos à devastação ambiental ocorrida nos Municípios paraenses no mesmo período.

\section{A ECONOMIA E SUA RELAÇÃO COM O MEIO AMBIENTE}

Desenvolvimento econômico e preservação do meio ambiente, em geral, são considerados elementos opostos. A opulência do capitalismo e sua busca desenfreada por lucro sempre deixaram em segundo plano qualquer outro fator que se opusesse a tal sistema. A Revolução Industrial ${ }^{3}$, acelerou o processo de produção de bens e, consequentemente, os lucros dos industriais. Esse período compreendido entre o final do século XVIII e início do século XIX, foi uma época de profundas transformações econômicas e sociais que foi marcada pelo aumento da população urbana e pela miséria da classe trabalhadora que se amontoavam em cortiços e trabalhavam em condições degradantes. Marx e Engels (2012, p. 220) previa o colapso do sistema:

[...] O desenvolvimento da indústria moderna, portanto, enfraquece o próprio terreno em que a burguesia assentou a produção e a apropriação de seus produtos. Assim, a burguesia produz, sobretudo, seus próprios coveiros. Sua queda e a vitória do proletariado são igualmente inevitáveis.

Piketty (2014, p. 09) contesta Marx:

O crescimento econômico moderno e a difusão do conhecimento tornaram possível evitar o apocalipse marxista, mas não modificaram as estruturas profundas do capital e da desigualdade.

Do outro lado, economistas liberais previam que o próprio sistema se encarregaria de diminuir a desigualdade, como é o caso do economista russo Kuznets (1955), que segundo a sua teoria:

[...] A desigualdade de renda deveria diminuir de modo automático nos estágios mais avançados do desenvolvimento capitalista de um país, a despeito das políticas adotadas ou da diferença entre os países, até que se estabilizasse num nível aceitável.

\footnotetext{
${ }^{3}$ Ocorrida na Inglaterra entre os anos de 1760 a 1840, onde houve uma mudança na forma de produção de bens, passando de um método de produção artesanal para a produção por máquinas.
} 
A teoria de Kuznets tem influência até nos dias atuais, e é considerada por muitos como a primeira teoria sobre crescimento e a desigualdade baseada em dados estatísticos, além de apresentar, já nessa época, uma preocupação com o meio ambiente ao associar desenvolvimento e meio ambiente.

Ao fazermos uma brevíssima análise do desenvolvimento das teorias econômicas no período pós revolução industrial, a indagação que fica é sobre o papel do Estado para evitar distorções no sistema capitalista e, consequentemente na diminuição das desigualdades sociais. A crise econômica global ocorrida em 2008 na opinião de muitos economistas, só não foi maior do que a ocorrida em 1929, que derrubou a bolsa de valores de Nova York e deixou o mundo em estado de pânico. A crise de 1929, apesar de grave, deixou grandes lições e, em certa medida, evitou que os estragos provocados em 2008 fossem maiores, pois, os governos e os bancos centrais dos países ricos atuaram de forma imediata, evitando falências e a bancarrota do sistema financeiro mundial. Não resta dúvidas que o papel que o Estado tem hoje na economia e na vida das pessoas é imensamente superior que o peso que tinha em 1930, trazendo como consequência óbvia, uma maior responsabilidade dos governantes com as desigualdades e seus efeitos.

Uma das conclusões abarcadas por Piketty (2014, p. 27) é que; “A história da distribuição da riqueza jamais deixou de ser profundamente política, o que impede sua restrição aos mecanismos puramente econômicos".

Como se vê, a discussão do papel do Estado hoje na vida das pessoas gira mais precisamente em, que ramos ele deve atuar e o seu tamanho. O governo deve ser o principal fiador dos direitos e garantias, individuais e coletivos dos cidadãos e, entre eles, o direito a um meio ambiente equilibrado, modulando e estimulando comportamentos através das políticas públicas com o fim último de promover o desenvolvimento sustentável, para isso, devem ser colocados em prática todos os mecanismos e instrumentos que o Estado possui para a consecução de seus objetivos.

Ao que tudo indica, alguns países da América Latina, entre eles, o Brasil, estão adotando um modelo de Estado intervencionista que planejam e executem políticas públicas gerando crescimento econômico sustentado e a inclusão social dos desfavorecidos.

Nos ensina Gentil e Michel (2009, p. 131) 
[...] A história do capitalismo é rica em exemplos que demonstram que crescimento econômico, emprego em alto nível, estabilidade de preços, aprofundamento do processo de industrialização e, particularmente, redução das desigualdades sociais não são resultados espontâneos do funcionamento dos mercados. Pelo contrário, exigem orientação e direção por parte do Estado e, fundamentalmente, força política e organizacional dos trabalhadores.

Nos parece evidente que em relação ao meio ambiente, o Estado deve atuar de forma intensa com o intuito não apenas de preservação ambiental, mas principalmente, para modular comportamentos, inclusive econômicos.

O governo, deve atuar de forma que, os mercados passem a enxergar a preservação ambiental sob uma perspectiva econômica, mas de desenvolvimento sustentável, aproveitando os recursos das florestas sem destruí-la, adotando políticas públicas com viés econômico, estimulando comportamentos e, principalmente, mudando uma concepção cultural e empresarial focada exclusivamente na obtenção do máximo benefício sem levar em consideração as variáveis ecológicas, sociais e culturais da região envolvida, tão importantes na qualidade de vida dos seres humanos.

\section{A TRIBUTAÇÃO AMBIENTAL COMO INSTRUMENTO DE POLÍticas PÚBLICAS}

A Constituição Federal de 1988 foi a primeira a tratar de forma direta da proteção ao meio ambiente, dando tamanha relevância ao tema, que reservou um capítulo específico para disciplinar a matéria em seu capítulo VI, artigo 225. Nesse sentido, para Tupiassu (2006, p. 120) “a proteção ambiental é um princípio básico da ordem constitucional econômica e, não se justifica se não servir à sua finalidade”.

O poder de tributar por parte do Estado, parece violar certos direitos fundamentais do cidadão, como o direito à propriedade e à liberdade, entretanto, não existe direito ilimitado, a tributação é essencial para a manutenção e financiamento das ações do próprio Estado, entre elas, as prestações sociais, que garantem a existência desses direitos fundamentais. Os tributos, servem tanto para arrecadar recursos para o funcionamento da máquina estatal (finalidade fiscal), como para induzir comportamentos desejados pelo governo como, regular o mercado, corrigir as externalidades negativas ou, "premiar" as externalidades positivas (finalidade extrafiscal), ou seja, a tributação extrafiscal é dirigida a fins outros que não a arrecadação de

Rev. de Direito Ambiental e Socioambientalismo | e-ISSN: 2525-9628 | Maranhão | v. 3 | n. 2 | p. 188 - 202 | Jul/Dez. 2017 
dinheiro para o erário público. O direito tributário pode, através de sua finalidade extrafiscal, estimular certos comportamentos nos entes econômicos, incentivando iniciativas positivas e, desestimulando as negativas utilizando-se de políticas públicas como é o caso do ICMS verde.

A extrafiscalidade é, como preconiza Falcão (1981, p. 48):

[...] A atividade financeira que o Estado exercita sem o fim precípuo de obter recursos para o seu erário, para o fisco, mas sim com vistas a ordenar ou reordenar a economia e as relações sociais.

No entendimento de Tupiassu (2006, p. 120):

[...] A utilização extrafiscal do tributo visa, acima de tudo, induzir a conduta dos contribuintes. Ao contrário do que se almeja através da função tributária tradicional (obtenção de recursos para o financiamento das atividades estatais), utilizando-se da extrafiscalidade o Estado busca, muitas vezes, uma "redução da arrecadação", seja através da imposição de altas cargas tributárias às condutas que visa reduzir, seja através da concessão de incentivos fiscais àqueles que se adaptam à conduta almejada.

Frise-se que, tanto a finalidade fiscal, quanto a extrafiscal, não se contrapõem, pelo contrário, elas são complementares e, algumas vezes, uma prevalecerá sobre a outra.

A orientação de condutas por meio da extrafiscalidade poderá ser realizada utilizandose duas técnicas de atuação: (1) por intermédio de incentivos fiscais; e (2) pelo estabelecimento da cargas tributárias (PERALTA, 2013, p. 181):

(1) Os incentivos fiscais. $O$ incentivo fiscal pode influenciar o comportamento almejado (comissivo ou omissivo), atribuindo-lhe consequências agradáveis ou facilitando-o. No primeiro caso, incentivase através do prêmio, intervindo nas consequências do comportamento como, por exemplo, na repartição de receitas de acordo com critérios ambientais no ICMS ecológico. No caso da facilitação, incentiva-se intervindo nas modalidades, nas formas e nas condições do comportamento, através de subsídios, isenções, créditos especiais, depreciações aceleradas etc. Trata-se de técnicas de estímulo com uma função de mudança social.

(2) As cargas tributárias. Por meio dos tributos são desestimulados comportamentos ou atos que, ainda que lícitos, são considerados prejudiciais para a sociedade. Com esse tipo de medida busca-se reorientar a conduta não desejada (comissiva ou omissiva), obstaculizando-a ou atribuindo-lhe consequências negativas. Nesse caso, trata-se de medidas de conservação social. A qualificação de um tributo como extrafiscal não dependerá apenas da finalidade expressada na norma jurídica, mas da estrutura impositiva utilizada para promover ou desestimular uma determinada atuação. 
Nota-se que a introdução da variável ambiental no sistema tributário brasileiro, associada a políticas públicas ambientais, tonaram-se um importante instrumento para internalizar os custos socioambientais, permitindo um equilíbrio entre os interesses econômicos e os interesses ambientais, tornando o sistema mais eficiente e eficaz na promoção do desenvolvimento sustentável.

Para que os Municípios onde estão situadas áreas de proteção ambiental possam formular políticas públicas de preservação do meio ambiente e promover o desenvolvimento sustentável, faz-se necessário a obtenção de recursos financeiros para a sua concretização.

O modelo fiscal de distribuição de receitas adotado pelo Brasil chamado de federalismo fiscal cooperativo, auxilia os Municípios na obtenção de tais recursos, além disso, a própria Constituição Federal de 1988 alçou os Municípios à categoria de entes federados, dotando-os de autonomia política, administrativa e financeira.

A Carta Magna de 1988, trata do tema federalismo fiscal, no título IV, capítulo I, entre os artigos 145 e 162, preconizando que, Estados e Municípios, participam das receitas tributárias tanto por meio de fundos como também na participação direta do produto de arrecadação de outros entes políticos.

É neste contexto de repartição de receitas estaduais para os Municípios que está inserido o ICMS Ecológico, pois, é a própria Constituição Federal, que estabelece, em seu artigo 158, IV e, parágrafo único, permissivo máximo para o montante a ser repassado, bem como, seus critérios.

O ICMS Ecológico tem seu fundamento calcado nesses critérios de distribuição de receitas estipulados pela Constituição Federal, onde o Estado do Pará, inseriu a variável ecológica para a distribuição desses recursos, surgindo assim, a política pública do ICMS Ecológico.

O ICMS Ecológico funciona, portanto, como uma espécie de compensação aos Municípios que sofrem "limitações" ao desenvolvimento de algumas atividades produtivas, em função da necessidade de manutenção de áreas com restrições ambientais no valor da transferência constitucional recebida com base no critério tradicional do valor adicionado. 
O instituto funciona, na verdade, como elemento incentivador de comportamentos, já que os Municípios buscarão adequar-se cada vez mais aos critérios socioambientais que servem como parâmetros ao repasse, de modo a aumentar seu índice de participação na quota-parte.

\section{ICMS ECOLÓGICO COMO POLÍTICA FISCAL AMBIENTAL}

O conceito de política pública vem acompanhando as mudanças sociais. No entendimento de Giovanni (2009, p. 28):

[...] a ideia de política pública como uma simples intervenção do Estado em uma situação social perturbadora não condiz mais com a moderna doutrina, que a vê como uma forma contemporânea de exercício do poder nas sociedades democráticas, resultante de uma complexa interação entre o Estado e a sociedade, o uso de políticas públicas nesta acepção, vem se tornando cada vez mais comum nas sociedades democráticas, de forma que, sua execução, está diretamente ligada a qualidade da Democracia para a devida efetivação da cidadania.

É nessa perspectiva de Democracia participativa que se vislumbra a interação da sociedade com o poder público para a formulação de políticas públicas, principalmente na área ambiental, dada a sua proximidade com a comunidade afetada e, a própria fiscalização, que poderá ser feita por seus membros, garantindo dessa forma, uma maior efetividade à política pública implementada.

No que tange a relação entre direito e políticas públicas, percebe-se que são institutos autônomos, mas interdependentes, uma vez que, as decisões políticas são efetivadas através do direito, este sistema tem início na Constituição, perpassando por uma distribuição de competências garantindo a horizontalidade entre os institutos.

No entendimento de Smanio (2013, p. 281)

[...] Tanto a decisão, quanto a realização das políticas e dos programas de ação do Estado também ocorrem na esfera jurídica e, principalmente, através da esfera jurídica, que condiciona e regula a atuação do Estado, inclusive nesta área de atuação. Daí a indispensabilidade de conceituarmos as Políticas Públicas como fenômeno jurídico, percebemos sua natureza jurídica, estabelecemos o regime jurídico aplicável à atuação do Estado e também dos demais partícipes de sua execução.

Dentro da esfera do direito, mais precisamente, o direito tributário e o sistema tributário nacional oferecem ao poder público uma ferramenta importante para a implementação de políticas públicas, ferramenta essa, que tem origem na forma do Estado Federal esculpida em nossa Constituição. 
Nessa perspectiva Domingues (2007, p.35) explica:

[...] Há no Brasil, através do sistema tributário nacional (título VI, capítulo I da Constituição), uma partilha constitucional de rendas que corresponde à divisão constitucional de competências político - administrativas entre a União (art.21), os Estados (art.25), o Distrito Federal (art.32) e os Municípios (art.30). Outra vertente dessa partilha de rendas, é o regime de participação de Estados e Municípios no produto da arrecadação de impostos federais e estaduais (arts. 157, 158 e 159 da Constituição). Como a carta enseja aos Estados que estabeleçam critérios complementares para a distribuição dos recursos provenientes do ICMS (art. 158, parágrafo único, II) - imposto sobre a circulação de mercadorias e serviços.

Nessa linha de raciocínio, seguindo o princípio do federalismo fiscal, $25 \%$ da arrecadação do $\mathrm{ICMS}^{4}$ feita pelos Estados são repartidas com os Municípios e, dessa quota-parte de $25 \%, 3 / 4$ (três quartos) serão distribuídos proporcionalmente ao Valor Adicionado Fiscal (VAF) ${ }^{5}$ das operações realizadas no território do Município; e 1/4 (um quarto) será distribuído de acordo com os critérios fixados pela legislação estadual.

Dentro desta abertura conferida pela Constituição é que surge a política do ICMS Ecológico.

É importante salientar que, o ICMS verde, não é um novo imposto criado com intuito de preservação de nossas florestas, trata-se de um mecanismo de redistribuição de receitas públicas, oriundo do federalismo fiscal e, devidamente positivado na Constituição Federal e legislação estadual, concedendo aos Estados uma certa margem de discricionariedade na distribuição de tal receita, havendo apenas, uma mudança no critério de repartição, sendo introduzida a variável ecológica com fim indutor de comportamento, que vem a ser uma característica do sistema tributário nacional.

O ICMS Ecológico é, portanto, um instrumento tributário que permite aos Municípios receber parcelas maiores do ICMS que é repassado pelos Estados em razão do atendimento de determinados critérios ambientais estabelecidos na legislação estadual. Trata-se, assim, de uma nova forma de distribuição de receitas baseada no princípio do federalismo fiscal, tendo como fim último a preservação do meio ambiente.

\footnotetext{
${ }^{4}$ Imposto sobre operações relativas à circulação de mercadorias e sobre prestações de serviços de transporte interestadual e intermunicipal e de comunicação (art. 155, II e seus $\S \S 2^{\circ}, 3^{\circ}, 4^{\circ}$ e $5^{\circ}$, no art. 158, IV, e no art. 147, todos da Constituição da República.

${ }^{5} \mathrm{O}$ Valor Adicionado Fiscal (VAF) corresponde ao valor das mercadorias saídas, acrescido do valor das prestações de serviços, realizadas no território de cada Município, deduzido o valor das mercadorias entradas em cada ano civil.
}

Rev. de Direito Ambiental e Socioambientalismo | e-ISSN: 2525-9628 | Maranhão | v. 3 | n. 2 | p. 188 - 202 | Jul/Dez. 2017 
O primeiro Estado a adotar o ICMS Ecológico foi o Paraná em 1989. Hoje, 18 Estados brasileiros já adotam tal mecanismo. Essa política visa, recompensar e estimular os Municípios que investem na preservação ambiental em seus territórios.

O objetivo do ICMS Ecológico é premiar e compensar os Municípios detentores de grandes áreas de preservação ambiental em seu território e que, por esse motivo, poderiam ter o seu desenvolvimento limitado, uma vez que, a política fiscal do ICMS, visa as relações de entrada e saída de mercadorias e os serviços prestados em determinado local.

A utilização da variável ecológica na distribuição de receitas do ICMS, permite aos Municípios, a preservação das áreas ambientais protegidas sem que ocorra perda de receitas fiscais, bem como, a promoção do desenvolvimento sustentável e a melhora da qualidade de vida da comunidade.

A configuração do ICMS Ecológico em cada ente federativo que o adota corresponde um verdadeiro redimensionamento de valores (SCAFF; TUPIASSU, 2005, P. 746), tanto sob a perspectiva axiológica, quanto financeira.

Neste sentido, a depender do objetivo almejado com o estabelecimento da política em cada ente federativo, sua formulação deve ser avaliada.

Assim, a definição dos critérios de repasse corresponde a uma opção estratégica e também política de cada Estado, devendo ser compreendida dentro de cada contexto específico, analisando-se as bases influenciadoras da decisão normativa e os efeitos com ela buscados.

Para representar uma política pública ambiental, portanto, o ICMS Ecológico precisa configurar-se de modo a efetivamente atingir os fins a que se destina. Tal tarefa, porém, nem sempre é efetivamente obtida, merecendo análises, avaliações e reestruturações meticulosas.

\section{O ICMS ECOLÓGICO NO ESTADO DO PARÁ}

No Estado do Pará, o ICMS ecológico foi introduzido pela Lei estadual $\mathrm{n}^{\circ} 7.638$ de 2012 (PARÁ, 2012), regulamentada pelo Decreto estadual nº 775 de 2013 (PARÁ, 2013), posteriormente substituído pelo Decreto estadual nº 1.696 de fevereiro de 2017(PARÁ, 2017). Hoje, $8 \%$ do valor repassado aos Municípios referente ao ICMS pelo Estado do Pará, seguem critérios ecológicos determinados pela Lei estadual $n^{\circ} 7.638 / 2012$ como a existência no território municipal, de unidades de conservação e outras áreas ambientalmente protegidas, bem 
como a participação dos Municípios em sua implementação e gestão, tais critérios, serão melhor estudados no decorrer deste artigo.

A Lei estadual $n^{\circ} 7.638 / 2012$ considera como critério ecológico a existência, no território municipal, de unidades de conservação ${ }^{6}$ e outras áreas ambientalmente protegidas ${ }^{7}$, bem como a participação dos Municípios em sua implementação e gestão. A Lei 7.638/2012 preconiza, também, como áreas protegidas, as estradas cênicas, os rios cênicos, as reservas de recursos naturais, as áreas de populações tradicionais, as áreas e terras indígenas, as áreas de preservação permanente e de reserva legal.

Os critérios previstos na Lei estadual $\mathrm{n}^{\circ}$ 7.638/2012, foram regulamentados pelo decreto estadual $n^{\circ} 1.696 / 2017$, que criou quatro fatores, com pesos distintos, que servem para classificar o esforço ambiental dos Municípios.

O primeiro fator, denominado de regularização ambiental, avalia o esforço dos Municípios em relação aos processos de adequações ambientais dos produtores rurais, e é composto pelo cadastro ambiental rural - CAR; área de preservação permanente - APP; reserva legal - RL; e pela área degradada - AD.

O segundo fator, denominado de gestão territorial, representa a dimensão que mede o impacto territorial das áreas protegidas e a gestão sobre as unidades de conservação, e é composto pelas áreas protegidas de uso restrito; áreas protegidas de uso sustentável; deflorestamento e deflorestamento em áreas protegidas.

O fator 3, denominado de estoque florestal, representa a dimensão que mede o remanescente florestal do Município analisado, ou seja, o percentual de cobertura vegetal ainda existente, e é formado por uma única variável (remanescente florestal).

O último fator, denominado de fortalecimento da gestão ambiental municipal, representa a dimensão que mede a capacidade de exercício da gestão ambiental municipal para licenciamento de impacto local, fiscalização e outras atividades, e é composto por uma única variável (capacidade de exercício da gestão ambiental).

Na explicação de Tupiassu (2017, p. 12);

\footnotetext{
${ }^{6}$ As unidades de conservação são categorizadas como unidades de proteção integral e de uso sustentável pelo Sistema Nacional de Unidades de Conservação da Natureza (SNUC).

${ }^{7}$ O Sistema Estadual de Unidades de Conservação (SEUC) prevê a possibilidade de criação de novas categorias de manejo.
}

Rev. de Direito Ambiental e Socioambientalismo | e-ISSN: 2525-9628 | Maranhão | v. 3 | n. 2 | p. 188 - 202 | Jul/Dez. 2017 
[...] é a partir do atendimento desses fatores que será aplicada uma fórmula para identificar quanto cada Município receberá por ocasião do repasse dos recursos. Os dados anuais referentes aos fatores citados são computados pela SEMAS, que aplica uma fórmula e, dessa forma, obtêm-se os índices de repasse de ICMS verde, que cada Município receberá no ano posterior.

Em 2017, o Instituto de pesquisa ambiental da Amazônia - IPAM, divulgou estudo (AZEVEDO; MOUTINHO; STABILE, 2016, p. 05) sobre o desmatamento na Amazônia com resultados preocupantes. Nessa análise verificou-se que o desmatamento em 2016 foi o mais alto desde 2008, atingindo praticamente $8.000 \mathrm{Km}^{2}$. Com aumento de $28,7 \%$ em relação à 2015 , tal resultado, é alarmante principalmente no Estado do Pará. Este Estado, em termos absolutos, foi o que mais desmatou. Nele constatou-se um aumento de $41 \%$ em relação à 2015 , com uma área total de $3.025 \mathrm{Km}^{2}$ de desmatamento. Entre os dez Municípios amazônicos que mais desmataram em 2016, cinco estão localizados no Pará, são eles: Altamira, São Félix do Xingu, Novo Repartimento, Portel e Novo Progresso. Desses, o campeão no desmatamento foi o Município de Altamira.

Em relação ao mesmo período, a Secretaria de Meio Ambiente e Sustentabilidade (SEMAS) divulgou a tabela dos valores de ICMS Verde repassados em janeiro de 2017, aos Municípios do Pará ${ }^{8}$. No total do mês de 2017, foram repassados aos Municípios que atenderam os critérios ambientais da política o montante de $\mathrm{R} \$ 14.421 .777,97$.

O que chama a atenção diante dos números apresentados pela SEMAS, é que o Município paraense que mais recebeu recursos do ICMS Verde foi Altamira (R \$ 285.746,65), justamente o Município campeão de desmatamento na Amazônia em 2016, segundo os dados do IPAM. Os outros Municípios presentes na lista do IPAM, também estão entre os dez que mais receberam recursos do ICMS Ecológico.

Esses números quando contrastados, em um primeiro momento, não refletem os objetivos almejados com a política pública do ICMS Ecológico intentada com a Lei estadual $\mathrm{n}^{\circ}$ 7.638/2012, que é a preservação ambiental consignada com o desenvolvimento sustentável.

Vários outros trabalhos chegaram à mesma conclusão (OLIVEIRA, TUPIASSU, 2016; FERREIRA, 2016).

\footnotetext{
${ }^{8}$ Conforme dados obtidos no site https://www.semas.pa.gov.br/
} 
Nota-se, portanto, indícios de que a formulação da política apresenta distorções, de modo que os critérios utilizados para os repasses dos recursos não se coadunam com os fins efetivamente almejados em sua formulação. Há a necessidade de estudos mais detalhados, principalmente em relação aos critérios de repasses desses recursos, a fim de identificar em que pontos surgem tais distorções, possibilitando uma reconfiguração da estratégia para adequá-la à perspectiva de política pública ambiental inicialmente buscada.

\section{CONSIDERAÇÕES FINAIS}

Diante do exposto, sustenta-se a ideia da necessidade do Estado intervir em determinadas áreas importantes da sociedade com o objetivo de garantir a efetivação dos direitos fundamentais positivados em nossa Constituição Federal, diminuindo as desigualdades sociais, promovendo o desenvolvimento sustentável e, para a consecução desses objetivos, o Estado pode se valer do uso de políticas públicas de várias matizes, entretanto, para o seu sucesso, urge a necessidade dessas políticas serem precedidas de amplo estudo de seus impactos e efeitos sobre a sociedade, debates públicos entre os partícipes e, sobretudo, muita cautela no seu desenvolvimento, especialmente na Amazônia, palco de muitos conflitos fundiários e econômicos.

O uso de instrumentos financeiros e tributários conjugados com políticas públicas sérias voltadas para a preservação ambiental configura-se como uma alternativa que deve ser levada em consideração pelos entes públicos. Há experiências de sucesso em outros Estados que adotaram tal mecanismo. O ICMS verde no Estado do Pará é recente, foi normatizado em 2012 e, estudos ainda são necessários, principalmente em relação aos critérios de repartição e ao mecanismo de cálculo desses repasses que é baseado em uma fórmula, ainda não muito bem definida. Tais critérios necessitam serem revisitados, reavaliados e rediscutidos. O Pará, possui 144 Municípios e, $100 \%$ deles, cumprem com todas as exigências expressas no decreto $\mathrm{n}^{\circ}$ 1.696/2017, uma maior rigidez na observância dos requisitos de repasse, exigiria um maior esforço dos Municípios ao cumprimento dos critérios.

Por fim, faz-se mister ressaltar que, apesar dos esforços feitos, muito ainda há pela frente. A História nos mostra que países que atingiram um alto grau de desenvolvimento, passaram, antes de tudo, por políticas educacionais sérias conjugadas com outras áreas importantes para o desenvolvimento do ser humano, este porém, não é nosso objeto de estudo, 
porém, nos parece um fator importante para a consecução da preservação ambiental. A utilização de instrumentos tributários e econômicos em políticas públicas voltadas para a preservação ambiental e ao desenvolvimento sustentável, mostrou-se eficiente em outros países que adotaram tal veículo. O Estado do Pará, possuidor de um vasto território verde, que urge pela sua preservação, não pode negligenciar sua riqueza e, cabe ao Estado e a sua população, a formulação de novas matrizes econômicas voltadas à manutenção de suas florestas e ao desenvolvimento sustentável.

Nessa perspectiva, o ICMS ecológico mostra-se como uma política pública de grande potencialidade para o alcance de tais objetivos, necessitando, porém, de ajustes em sua configuração e operacionalização.

\section{REFERÊNCIAS}

AZEVEDO, A. Alencar. Panorama sobre o desmatamento da Amazônia em 2016. Brasília. IPAM. 2016.

BORREO MORO, Cristobal J. La Tributacion Ambiental em España. Madrid. Tecnos. 1999 CARVALHO, Paulo de Barros. Curso de Direito Tributário. Rio de Janeiro. Saraiva. 2016. FALCÃO, Bezerra. Tributação e Mudança Social. Rio de Janeiro. Forense. 1981

FERREIRA, L. ICMS Verde: um estudo sobre a adequação de seus indicadores à sustentabilidade amazônica. Dissertação (Mestrado). Direito Políticas Públicas e Desenvolvimento Regional. Centro Universitário do Estado do Pará. Belém, 2016.

KUZNETS, Simon. Economic growth and income inequality. The American economic review, Vol. 45, No. 1, Mar., 1995, pp 1-28.

MARX K., ENGELS, F. R. Manifesto do Partido Comunista. São Paulo: Schwartz, 2012.

PERALTA, Carlos Eduardo. Tributação Ambiental: Reflexões sobre a introdução da variável ambiental no Sistema Tributário. São Paulo. Saraiva. P. 181. 2013.

PIKETTY Thomas. O capital no Século XXI. Rio de Janeiro. Intríseca p. 92014.

OLIVEIRA, José Marcos Domingues de. Direito Tributário e Meio Ambiente. São Paulo: Forense, 2007.

OLIVEIRA, Adriano. TUPIASSU, Lise. ICMS verde para a redução do desmatamento Amazônico: estudo sobre uma experiência recente. Veredas do Direito, Belo Horizonte, v.13, n. 25, p. 277-306, Janeiro/Abril, 2016.

PARÁ (Estado). Lei $n^{\circ} 7.638 / 2012$. Dispõe sobre o tratamento especial de que trata 0 \$ $2^{\circ}$ do art. 225 da Constituição do Estado do Pará. 2012. Disponível em: http://www.sefa.pa.gov.br/LEGISLA/leg/estadual/ICMS/le07638_12.htm. Acesso em: 14 fev.2014. 
PARÁ (Estado). Decreto $n^{\circ} 775$, de 26 de junho de 2013. Regulamenta a Lei Estadual $\mathbf{n}^{\circ}$ 7.638/2012, de 12 de julho de 2012. Disponível em http://www.sefa.pa.gov.br/LEGISLA/leg/estadual/DecinstNormPortarias/Decretos/dc00775_1 3.htm. Acesso em: 14 de agosto de 2017.

PARÁ (Estado). Decreto n ${ }^{\circ} 1.696$, de 97 de fevereiro de 2017. Revoga o Decreto Estadual n $^{\circ}$ 775, de 26 de junho de 2013, dando nova regulamentação a Lei Estadual $n^{\circ} \mathbf{7 . 6 3 8}$, de 12 de julho de 2012, e dá outras providências. 2017. Disponível em https://www.semas.pa.gov.br/2017/03/07/decreto-no-1-696-de-fevereiro-de-2017. Acesso em: 14 de agosto de 2017.

SCAFF,F.F.; TUPIASSU, L. V. da C. Tributação e Políticas Públicas: O ICMS Ecológico. In: Tôrres, Heleno Taveira (org). Direito Tributário Ambiental. São Paulo: Malheiros 2005, p.724-748.

SEM, Amartya. Desenvolvimento como Liberdade. São Paulo: Companhia das Letras, 2010.

SMANIO, Gianpaolo Poggio. BERTOLIN, Patrícia Tuma Martins. O Direito e as Políticas Públicas no Brasil. São Paulo. Atlas. 2013

TUPIASSU, Lise. ICMS verde: A cidade que ganha para conservar a natureza. Belém: Best Amazônia/ UFPA, 2017.

TUPIASSU, Lise. Tributação Ambiental: A Utilização de Instrumentos Econômicos e Fiscais na Implementação do Direito ao Meio Ambiente Saudável. Rio de Janeiro. Renovar. 2006. 